\title{
Calidad bacteriológica del agua en los sitios de recolección de "conchas negras" (Anadara tuberculosa y Anadara similis) en Chinandega, Nicaragua
}

Erick José Sandoval Palacios y Agnes Saborío Coze

Centro de Investigación de Ecosistemas Acuáticos (CIDEA) Universidad Centroamericana. Correo electrónico: ericks@ns.uca.edu.ni

Recibido: febrero de 2008 / Aceptado: octubre de 2008

EL MOLUSCO ANADARA TUBERCULOSA O ANADARA SIMILIS, CONOCIDO EN Nicaragua como "concha negra", se extrae del fango de los esteros y por lo tanto recibe, por medio de las escorrentías, desechos orgánicos provenientes de la ganadería y contaminación por infiltración de agua proveniente de letrinas. Su hábitat y alimentación (filtradoras) hacen que estos moluscos sean susceptibles a contaminarse, aumentándose el riesgo para el ser humano al ser consumidas crudas. Se muestreó agua de los esteros Padre Ramos, Aserradores y El Realejo, y fue analizada bacteriológicamente con el objeto de valorar el contenido de Echerichia Coli, Salmonella spp y Vibrio parahaemolyticus.

Se observó que durante los meses de invierno los valores de E.coli estuvieron por encima de los límites permisibles y durante los meses de verano los niveles de E.coli estuvieron dentro de los límites permisibles. La bacteria Salmonella spp no se encontró en ninguno de los esteros estudiados, los niveles de Vibrio parahaemolyticus estuvieron dentro de los límites permitidos.

Se recomendó continuar la investigación para probar métodos de depuración para bajar los contenidos bacteriológicos en los moluscos "conchas negras".

Palabras clave: conchas negras / contaminación fecal / riesgo sanitario

\section{Introducción}

En años recientes se ha incrementado la preocupación del sector público por la inocuidad de los alimentos para el consumo humano. El caso de los moluscos recobra especial importancia pues estas especies viven en ambientes diversos y son filtradoras, convirtiéndose de esta manera en concentradoras de bacterias, virus y toxinas. 
Las conchas negras, moluscos bivalvos, habitan principalmente en las raíces del mangle rojo y filtran hasta 50 litros de agua por día, concentrando bacterias, virus y residuos químicos en sus tejidos. Dentro de los tejidos de las conchas negras las bacterias se conservan vivas ya que por el efecto de filtración de la concha obtienen los nutrientes necesarios para alimentarse y sobrevivir.

Para evitar el consumo de moluscos contaminados, algunos países han elaborado códigos de buenas prácticas de producción acuícola de los moluscos bivalvos y sobre todo se han determinado estándares permisibles (Jahnecke et al., 2002).

En Nicaragua la extracción de moluscos es una actividad totalmente artesanal y se ubica principalmente en la zona de los esteros Aserradores, Padre Ramos y El Realejo, zonas de mayor extracción de la concha negra, concentrando aproximadamente el 90\% de la extracción total del país (CIDEA, 2005).

Alrededor de 2000 personas están dedicadas a la extracción de conchas negras; la extracción promedio por persona es de siete docenas por día. La extracción anual calculada de las dos especies denominadas o conocidas como "conchas negras" (Anadara tuberculosa y Anadara similis) es de 1, 088,680 y 1, 368,780 respectivamente (CIDEA, 2005).

El Gobierno de Nicaragua decretó una veda de extracción de la "concha negra" como una medida para preservar el recurso (Gaceta, 2002). Esta veda prohíbe la extracción total de las dos especies durante el período comprendido entre el 15 de abril y el 15 de julio.

Esta investigación pretende contribuir con información para las autoridades ambientales y de salud pública para conocer el estado bacteriológico de las aguas en los sitios de extracción de las conchas y determinar la calidad de las mismas para el consumo humano. Se establece como objetivo principal la determinación de la calidad bacteriológica del agua circundante a los bancos de Anadara tuberculosa y Anadara similis en los esteros Padre Ramos, Aserradores y El Realejo. Para ello se analizaron diferentes bacterias como indicadores del estado de contaminación bacteriológica del agua.

La presencia de la bacteria Echerichia coli puede deberse a varias fuentes de contaminación ambiental como las excretas del ganado (Thelin y Gifford, 1983; Stoddard et al.,1998; Kress y Gifford 1984; Porter, 1997; y Moore et al., 1989). Otra fuente de contaminación son los seres humanos por la mala ubicación y/o construcción de las letrinas que están cerca de los cuerpos de agua, permitiendo de esta manera la infiltración de bacterias patógenas a esos cuerpos de agua (Coyne et al., 1996).

Otra bacteria analizada fue Salmonella spp, que al igual que la $E$. coli es de origen fecal, proveniente de animales de sangre caliente. Su presencia en productos pesqueros y acuícola frescos o congelados está prohibida (MIFIC, 2004 - NTON 03003 04).

Vibrio parahaemolyticus son bacterias que forman parte de la flora normal de un cuerpo de agua salobre. Hasta hace unos cuanto años se decía que este tipo de bacteria era solamente patógena para las especies acuáticas. Pero en Europa, Asia y los Estados Unidos de Norte América se han reportado casos de infecciones gastrointestinales causadas por ésta. 


\section{Materiales y método}

\section{1. Área de estudio}

El área de recolección de las muestras de agua se realizó en tres esteros ubicados en el noroccidente del país, zona de mayor extracción de dicho recurso. En la ilustración 1 se presentan los sitios en donde se hizo la recolección de las muestras de agua.

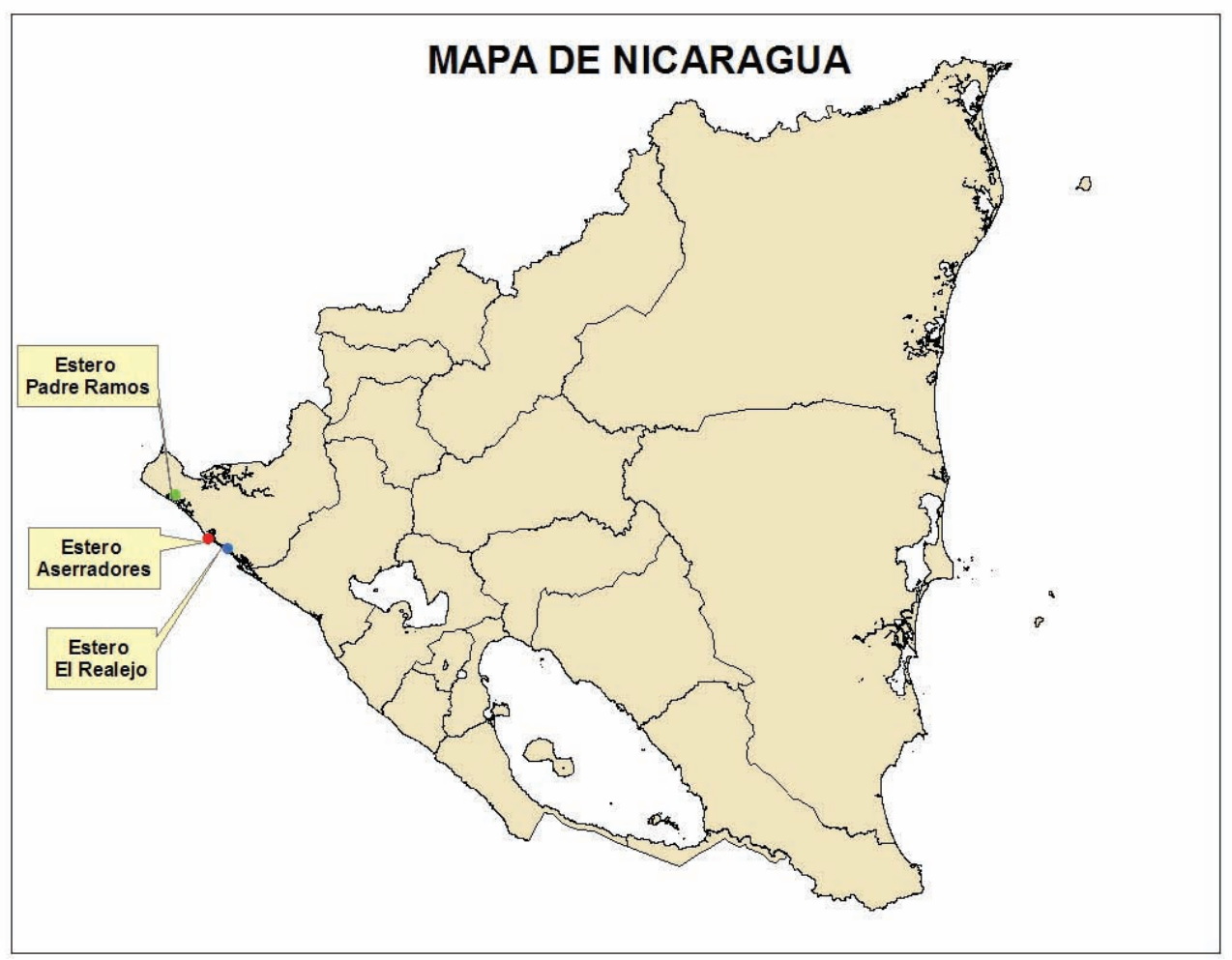

Ilustración 1. Mapa de Nicaragua con la ubicación del área de estudio 


\subsection{Puntos de muestreo}

La recolección de las muestras se realizó durante las mareas bajas en cada uno de los puntos seleccionados.

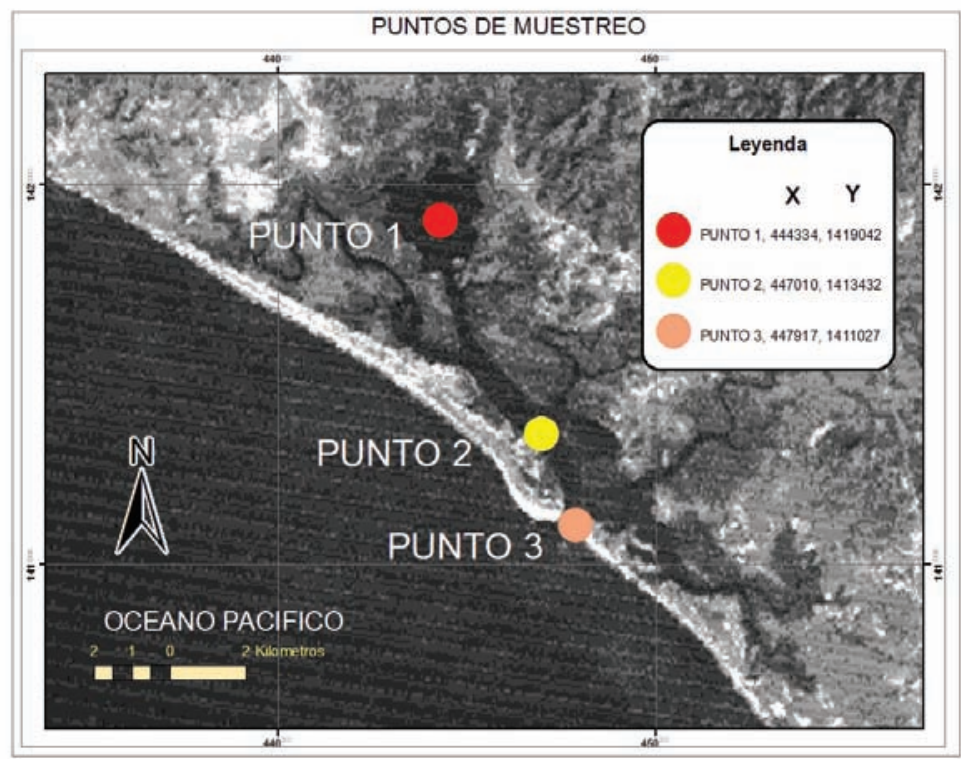

Ilustración 2. Puntos de muestreo en el estero Padre Ramos

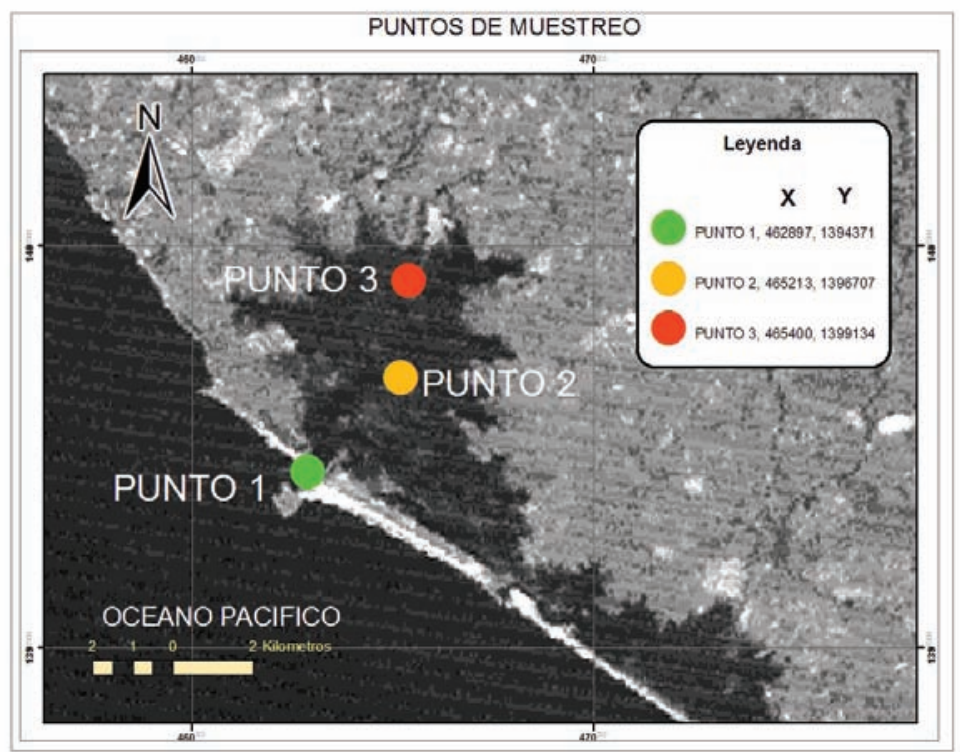

Ilustración 3. Puntos de muestreo en el estero Aserradores 


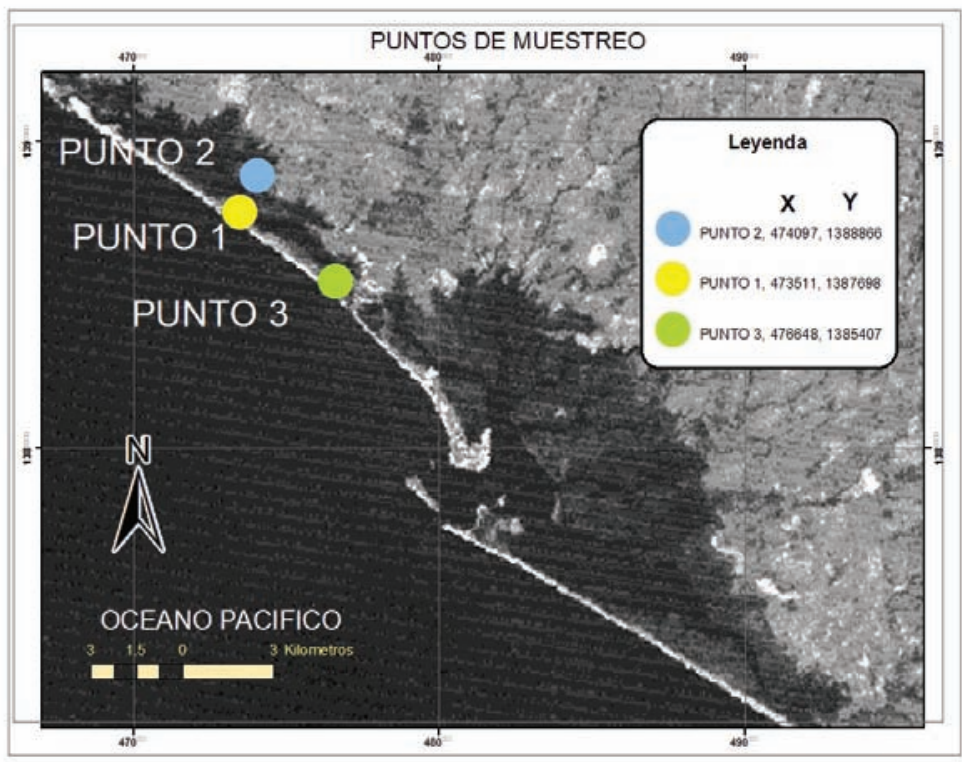

Ilustración 4. Puntos de muestreo en el Estero El Realejo

\subsection{Muestreo}

La toma de muestra se hizo con frascos plásticos estériles de un litro de capacidad. Se realizó introduciendo el frasco cerrado hasta una profundidad de $30 \mathrm{~cm}$. de la columna de agua. Alcanzada esa profundidad, se abrió el frasco y se llenó. Se dejó un espacio de aproximadamente $3 \mathrm{~cm}$. para facilitar la homogenización de la muestras. Se tomó la precaución de no tocar la superficie interna de los frascos para evitar la contaminación cruzada.

Las muestras se colocaron de inmediato en un contenedor provisto de una cama de hielo para climatizar la muestra. Al finalizar la toma de muestra de las tres zonas por estero, se cubrieron por completo de hielo, alcanzando las muestras temperaturas de $<10^{\circ} \mathrm{C}$. Se transportaron de inmediato al laboratorio para su análisis durante las primeras 24 horas.

\section{Análisis}

El conteo de E. coli se realizó por medio del método de Número Más Probable (NMP) más MUG, según el procedimiento del estándar método (APHA, AWWA, WEF, 1998). Los niveles permisibles utilizados para este estudio son los publicados por la EPA (agencia de protección del medio ambiente de los Estados Unidos de Norte América) en 1976, al igual que el CEPIS en 1986, donde limitan E. coli a $<43 \mathrm{NMP} / 100 \mathrm{ml}$.

La detección de Salmonella spp se realizó por medio del método de aislamiento de la bacteria. Este método es una modificación al Standard Método. Los niveles bacterianos 
utilizados son los publicados en la norma nacional NTON 0300304 donde dictan ausencia total de esta bacteria en cualquier producto pesquero o acuícola fresco o congelado. Por esta razón se determinó que el agua donde se encuentran estos moluscos debe de estar libre de Salmonella spp.

La detección de Vibrio parahaemolyticus se realizó por medio del método de aislamiento utilizado por la FDA (2004). Los niveles bacterianos utilizados son los recomendados por el CIAD, Mazatlán, México (<1.0x105 UFC/ml).

La recolección de las muestras se hizo por el personal del CIDEA-UCA y los análisis fueron hechos en el Laboratorio de microbiología del CIDEA-UCA, cuyos analitos han sido acreditados por la Oficina Nacional de Acreditación del país bajo la norma nacional NTN 04 00105 equivalente a la ISO/IEC 17025-05.

\section{Resultados}

\subsection{Estero Padre Ramos}

En el estero Padre Ramos se observó que el 36.11\% de las muestras de agua analizadas para Echerichia coli estuvieron por encima de los niveles permisibles decretados por la USEPA 1976 para pesca y cosecha de mariscos (valores menores a $43 \mathrm{NMP} / 100 \mathrm{ml}$ ). La media de las muestras que sobrepasaron los límites permisibles fue de $156.53 \mathrm{NMP} / 100 \mathrm{ml}$. Estos elevados niveles bacterianos inciden en la calidad bacteriológica de las conchas negras.

Cuadro 1. Resultados de E.coli en muestras de agua recolectadas en el estero Padre Ramos.

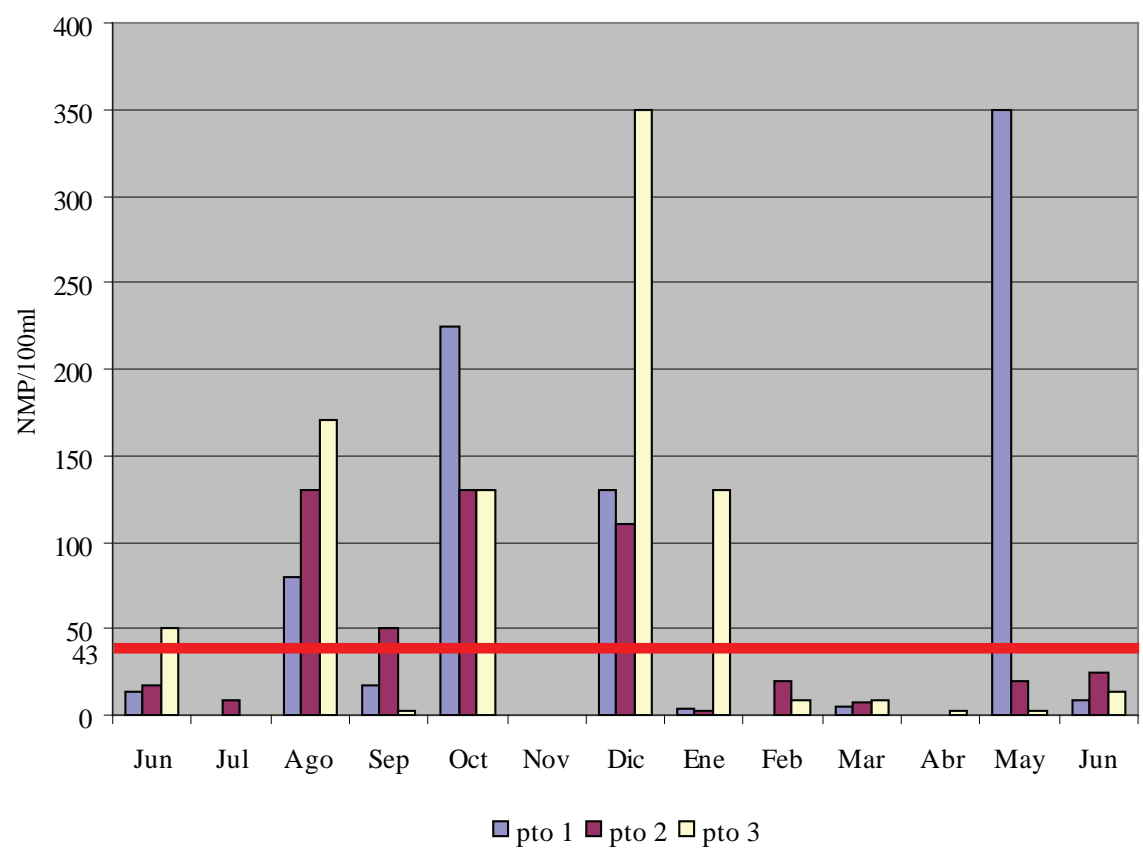


La incidencia encontrada en los tres puntos fue similar, es decir, de los meses de enero a mayo (época seca) menos del 10\% de las muestras mostraron valores mayores a los recomendados; a partir de la época de lluvia (junio a diciembre), los niveles se elevaron.

Para comprender esta situación se puede observar en el mapa de uso del suelo (Ilustración 5) que alrededor del estero hay pequeñas zonas de pastizales (ganadería). Muchos autores asocian esta actividad a problemas ambientales, ya que con las pezuñas el ganado provoca la permeabilidad del suelo, creando mayores escorrentías (Porter, 1997). La materia orgánica que deja este ganado en los pastos contiene millones de bacterias que pueden sobrevivir por períodos muy prolongados - incluso hasta de un año- en ese suelo (Stoddard et al., 1998, Thelin y Gifford 1983, Moore et al., 1989, Donsel et al., 1967, Davies et al., 1995). Cuando las lluvias caen la materia orgánica es arrastrada hacia los esteros, afectando la calidad bacteriológica de los cuerpos de agua. Pero la presencia humana también tiene un impacto, ya que la mala construcción o ubicación de las letrinas puede permitir la contaminación de los cuerpos de agua por el efecto de infiltración de las bacterias en el suelo (Coyne $e t$ al., 1996; Fulvio et al., 2004; y Stoddard et al., 1998).

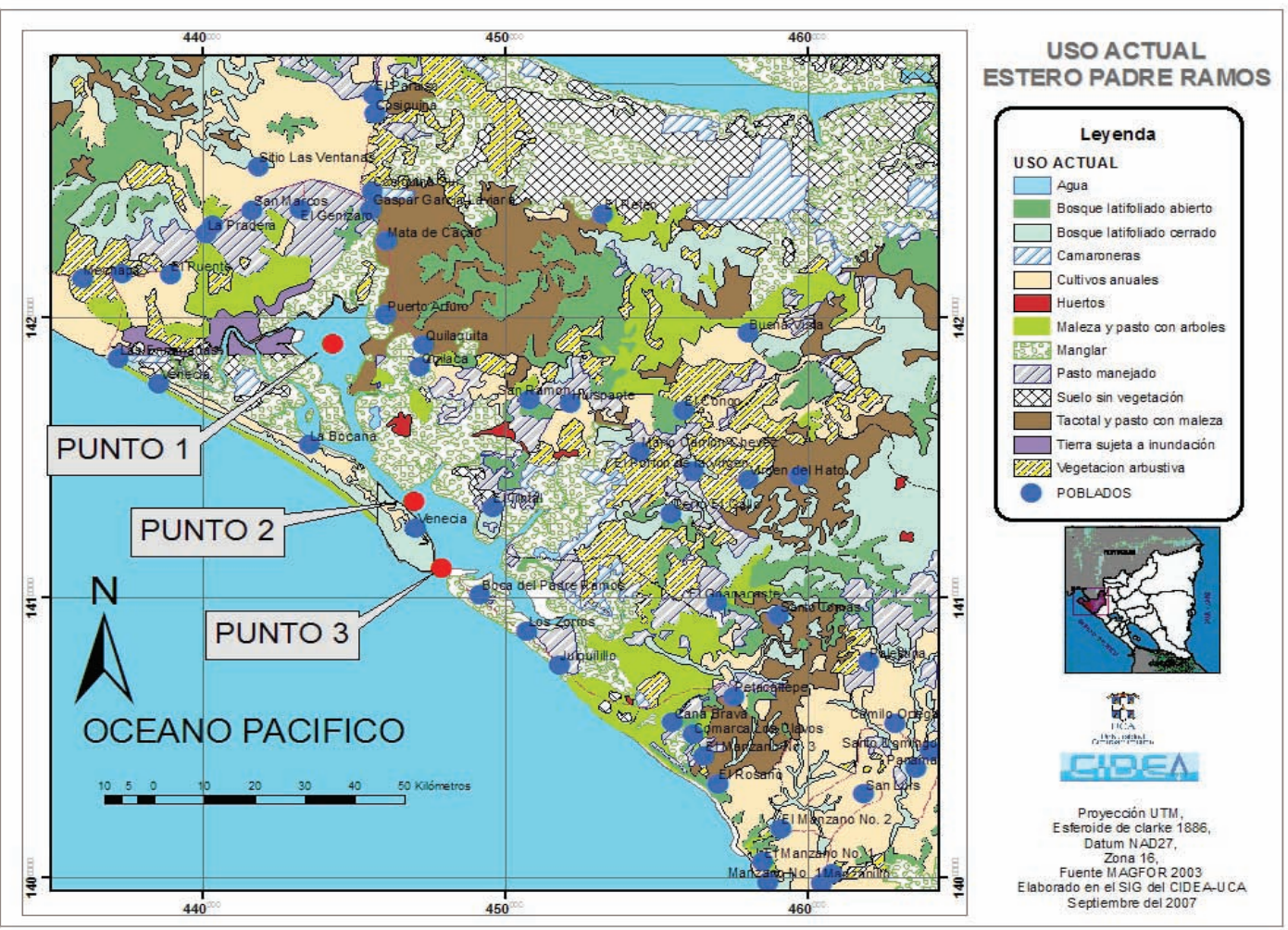

Ilustración 5. Mapa de uso actual, estero Padre Ramos 
$\mathrm{Al}$ analizar los niveles pluviométricos reportados por el INETER para el departamento de Chinandega durante 2006 y 2007, se encontró una correlación entre los niveles de coliformes versus los niveles pluviométricos de un 23.8\% (ver Cuadro 2).

Cuadro 2. Relación entre los registros pluviométricos de estación meteorológica vs. concentración $E$. coli encontrada en las muestras de agua

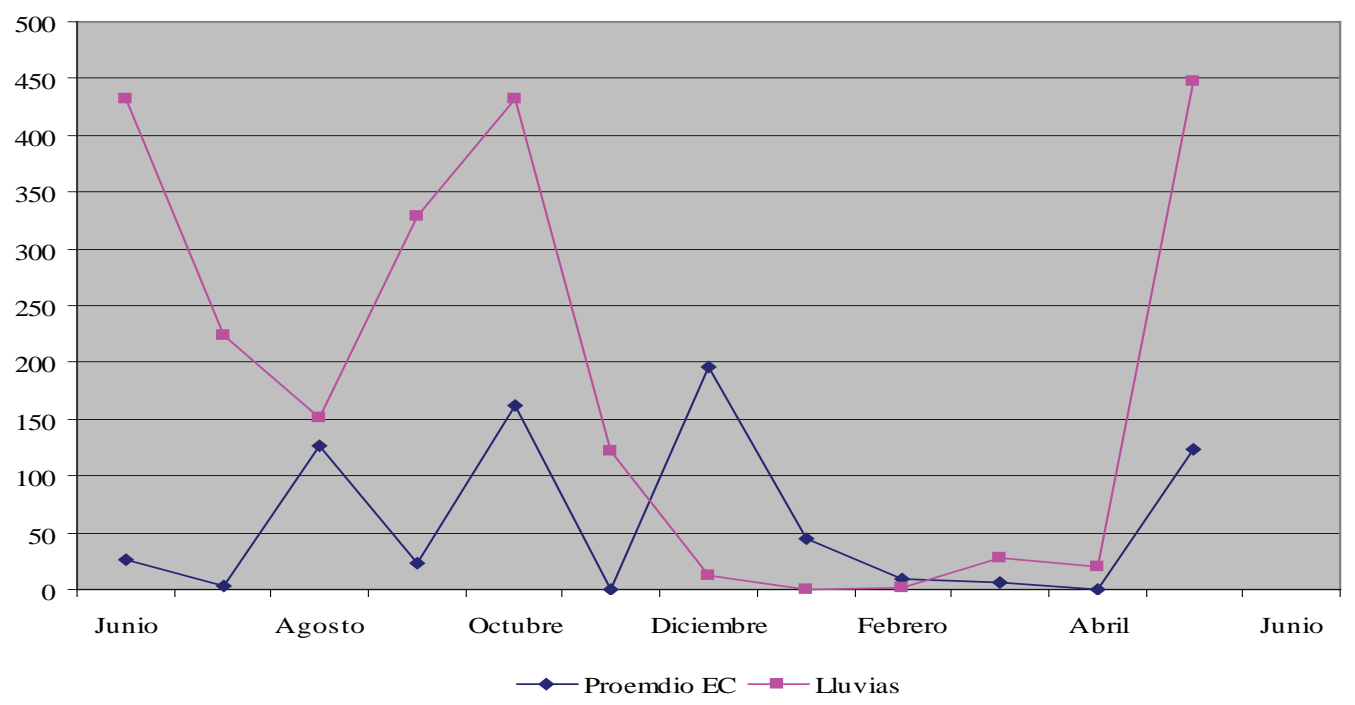

Los resultados de Salmonella spp indican que hay ausencia de esta bacteria en las aguas de este estero o que los niveles de esta bacteria son ínfimos. La sensibilidad del método aplicado por el laboratorio es (1 UFC/25 ml de agua.).

En referencia al Vibrio parahaemolyticus, los resultados mostraron que este tipo de bacteria ha permanecido dentro de los límites permisibles de 1.0x10 $\mathrm{UFC} / \mathrm{ml}$.

\subsection{Estero Aserradores}

En el estero Aserradores se observó que el 25\% de las muestras analizadas para E. coli estuvieron por encima de los niveles permisibles dictados por USEPA (ver Cuadro 3). La media de las muestras que estuvieron por encima de los límites permisibles fue de 170 $\mathrm{NMP} / 100 \mathrm{ml}$. 
Cuadro 3. Resultados de E.coli en muestras de agua recolectadas en el estero Aserradores.

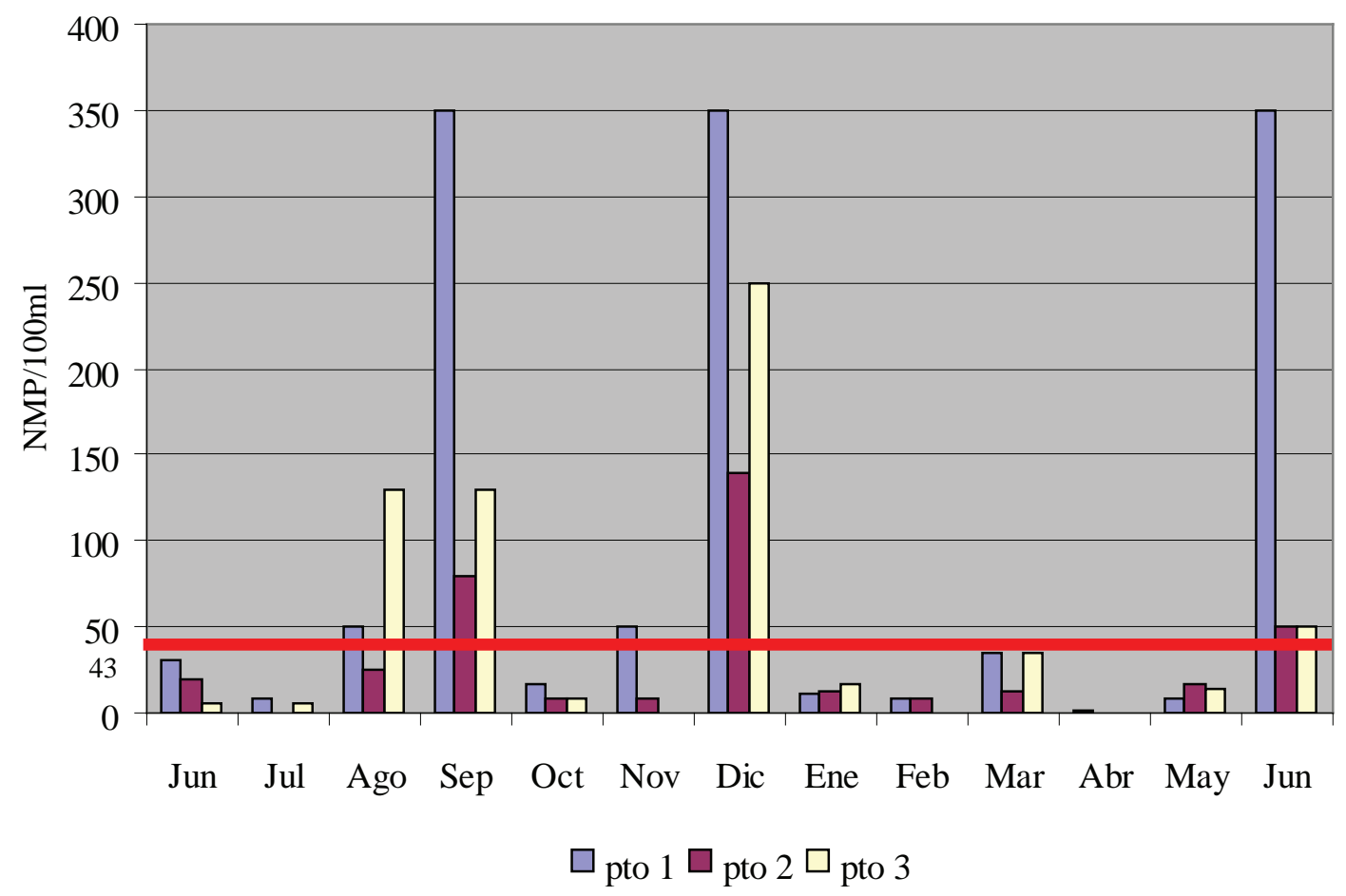

Dentro del estero, el punto 1 mostró el mayor nivel de contaminación (30\% de las muestras), seguido del punto 3 (23\%). El de menor contaminación fue el punto 2 con (15\%).

Como se puede apreciar en el mapa de uso del suelo del estero Aserradores (Ilustración 6), hay una gran actividad agrícola a su alrededor. Las tierras son utilizadas en cultivos anuales y cañaverales. Sin embargo, cerca del punto 1 hay una pequeña comunidad y una franja de tierra que es usada como pastizales (indicador de actividad ganadera), lo que podría explicar la contaminación del punto. En el mismo mapa podemos observar que el punto 3 tiene cerca un área de pastizal. Tanto el punto 1 como el 3 son los que mayores niveles de $E$. coli registran. En cambio, el punto 2 no tiene terrenos circundantes que sean utilizados como pastizales y es el que menos contaminación registra. 


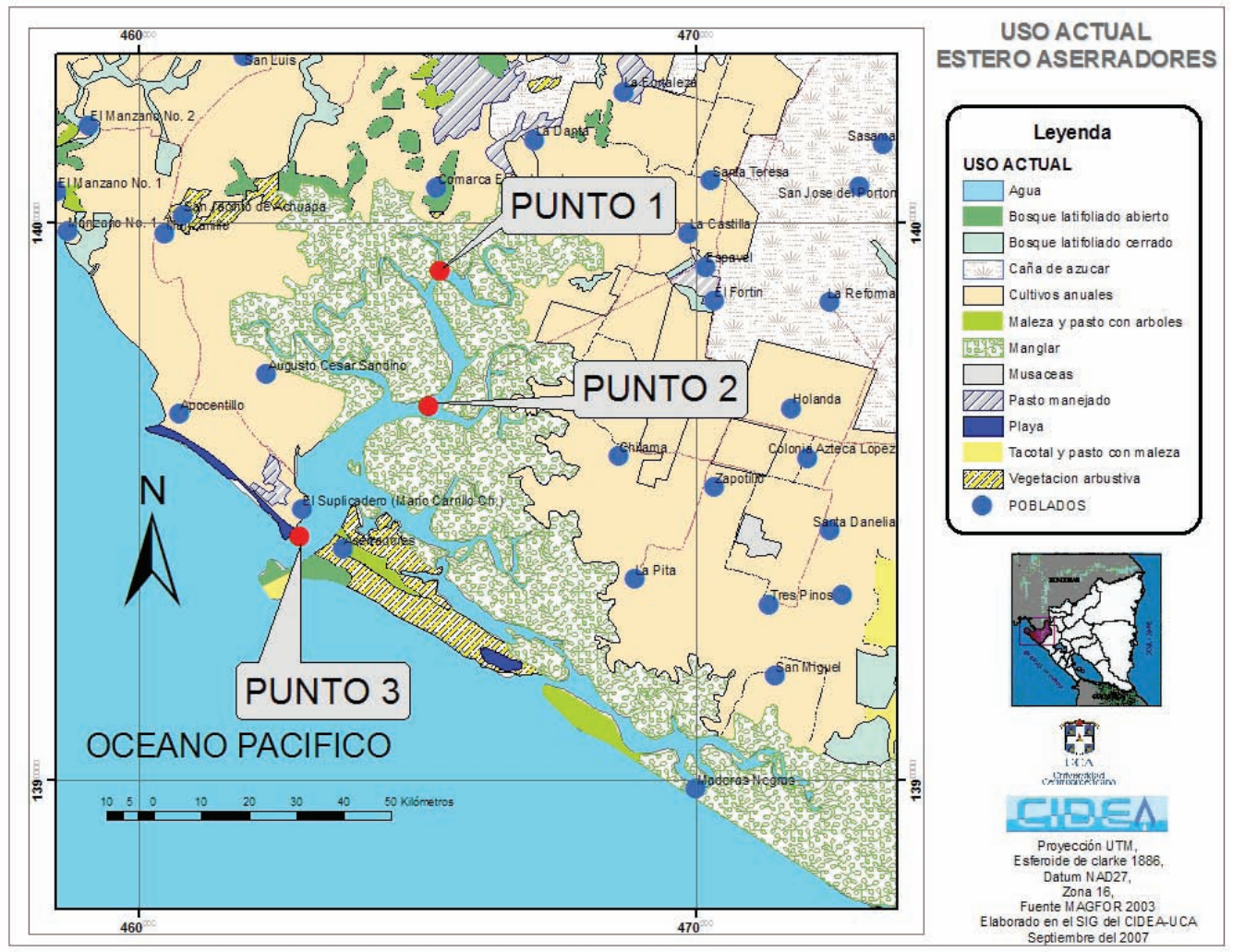

Ilustración 6. Mapa de uso actual, estero Aserradores

El análisis de correlación entre los niveles de coliformes vs. los niveles pluviométricos registrados por INETER arrojó la cifra de $-9.53 \%$, lo que indica que no hubo correlación entre estas dos variables. Sin embargo, está documentado el efecto de las precipitaciones pluviométricas en las concentraciones de bacterias (Donsel et al., 1967; Dewedar y Baghat, 1995; y Stoddard et al., 1998).

Los resultados obtenidos muestran que en este estero hay un predominio de niveles permisibles de $E$. coli, en los meses de época seca, que aumentan al final de la época lluviosa (septiembre a diciembre) (ver Cuadro 4). 
Cuadro 4. Relación entre los registros pluviométricos de estación meteorológica vs. concentración E.coli encontrada en las muestras de agua

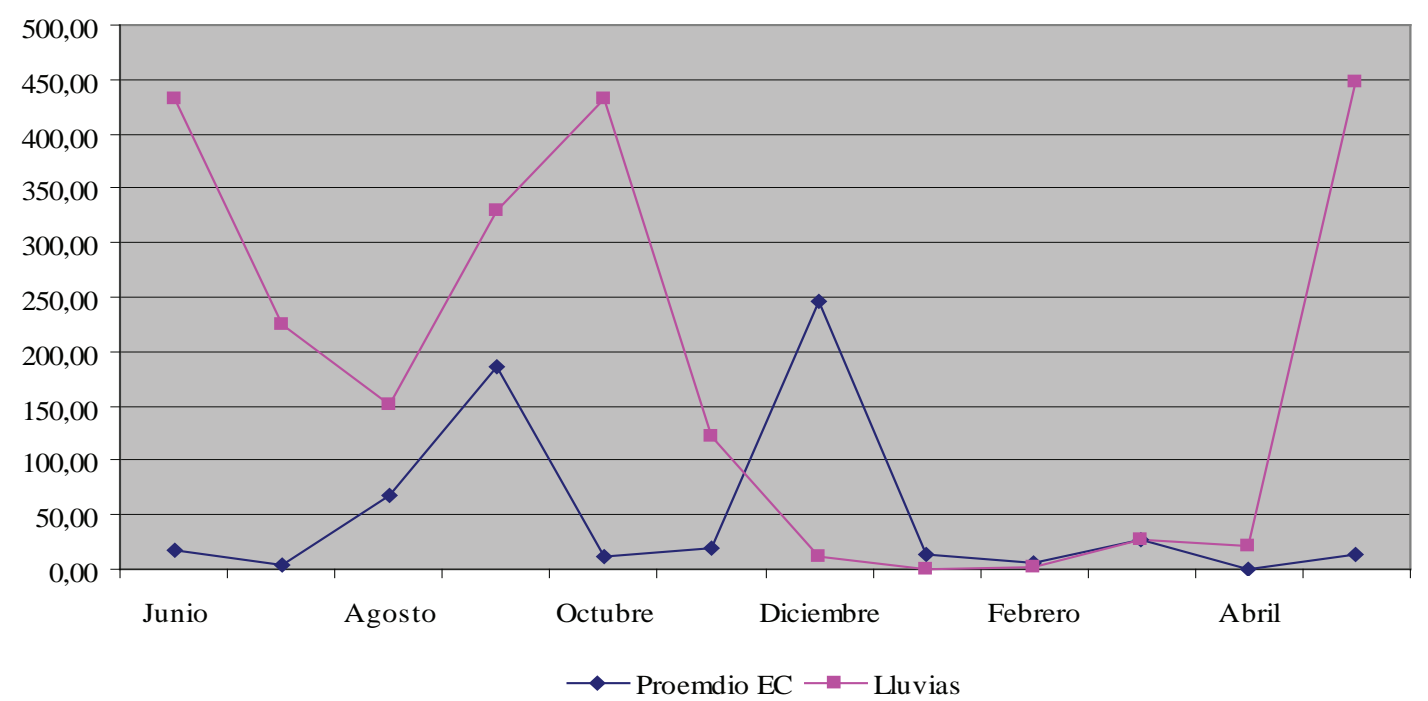

El análisis de Salmonella spp demuestra la ausencia de esta bacteria en este cuerpo de agua.

Los resultados de Vibrio parahaemolyticuslos en esta investigación han demostrado estar dentro de los límites permisibles $<1.0 \times 10^{5} \mathrm{UFC} / \mathrm{ml}$.

\subsection{Estero El Realejo}

En el estero El Realejo se observó que el 50\% de las muestras analizadas por E. coli estuvieron por encima de los niveles permisibles que dicta la USEPA (ver Cuadro 5); la media de los niveles elevados de $E$. coli fue de $220.53 \mathrm{NMP} / 100 \mathrm{ml}$. 
Cuadro 5. Resultados de E.coli en muestras de agua recolectadas en el estero El Realejo.

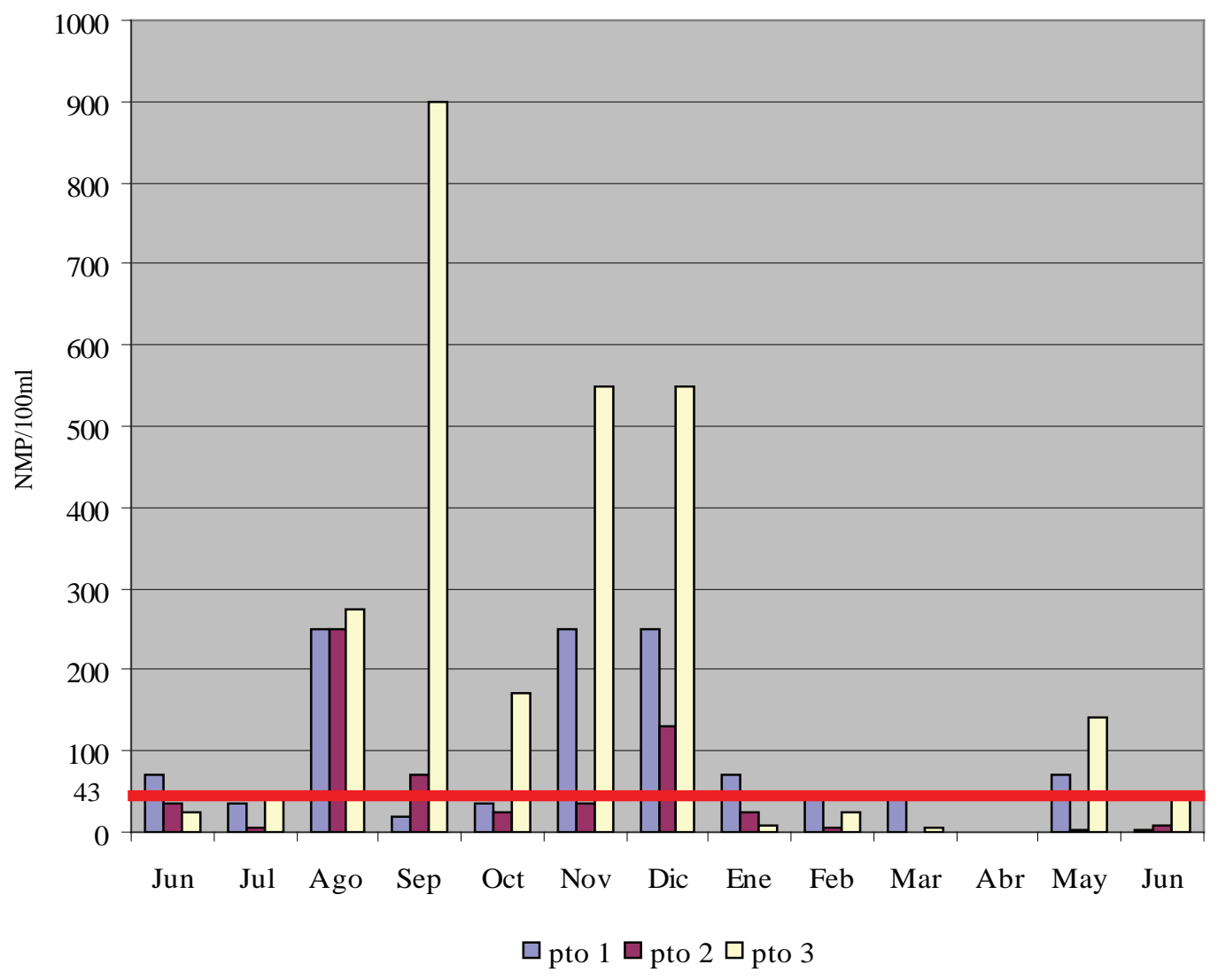

Dentro del estero el puntos 3 mostró los niveles más altos de contaminación (61\%), seguido del punto $1(46 \%)$. El punto de menor contaminación fue el punto $2(23 \%)$. Esto se debe a que en las zonas cercanas a los puntos $3 \mathrm{y} 1$ hay terrenos de pastizales utilizados por ganado vacuno (ver Ilustración 7), lo que explica la presencia constante de esta bacteria en estos puntos incluso en los meses de verano, aunque en menores concentraciones. Otra causa de contaminación que también podría estar afectando son los asentamientos humanos. 


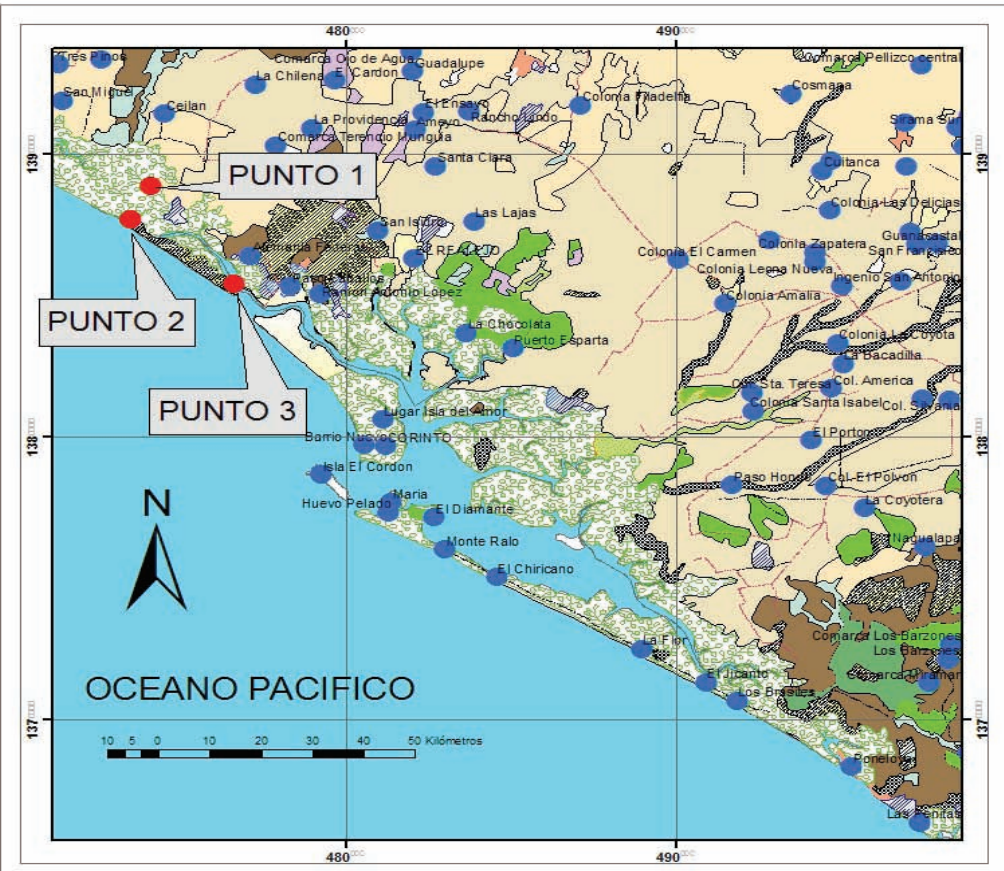

USO ACTUAL ESTERO EL REALEJO
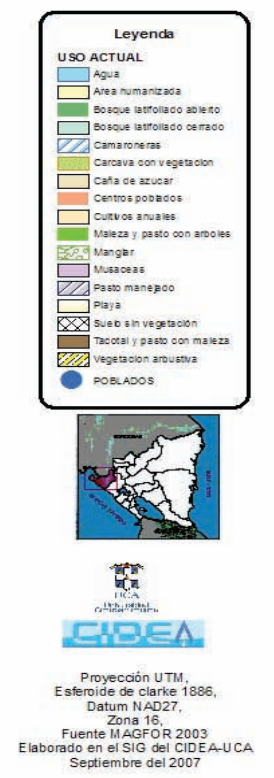

Ilustración 7. Mapa de uso actual, estero El Realejo

Entre los puntos 1 y 3 se puede apreciar que hay una franja de tierra que corresponde a terrenos utilizados como pastizales de ganado vacuno. Eso explicaría por qué sólo en estos dos puntos hay una prevalencia constante de bacterias $E$. coli tanto en los meses de verano como de invierno. Los terrenos colindantes al punto 2 son utilizados como cultivos anuales y cañaverales. También en este punto hay una pequeña extensión de tierra utilizada para pastizales de ganado vacuno. El análisis de coeficiente de correlación da un valor de $-1.20 \%$, lo que indica que no hubo correlación entre las dos variables. Sin embargo, está documentado el efecto de las precipitaciones pluviométricas sobre las concentraciones de bacterias (Donsel et al., 1967; Dewedar y Baghat, 1995; y Stoddard et al., 1998). 
Cuadro 6. Relación entre los registros pluviométricos de estación meteorológica vs. concentración E.coli encontrada en las muestras de agua.

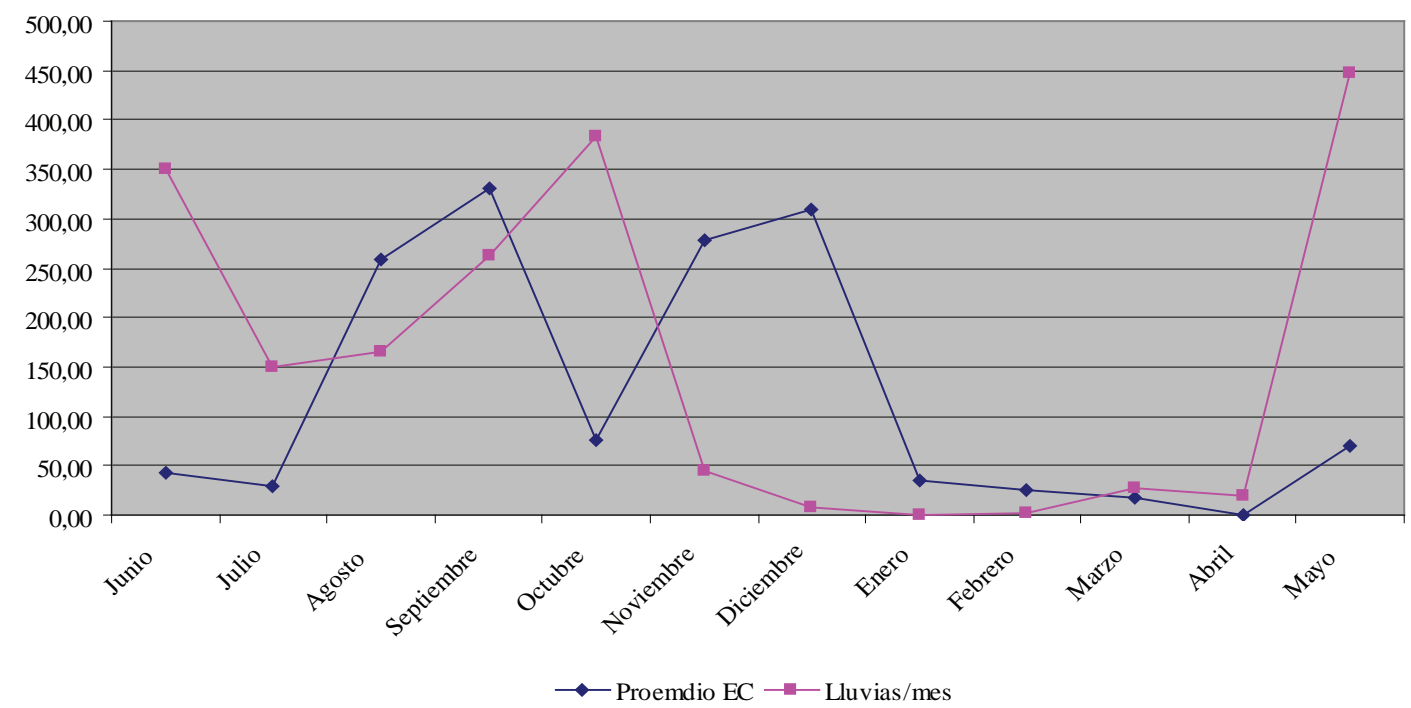

Aunque al igual que en los demás esteros analizados, la mayor contaminación por coliformes fecales se muestra en los meses de lluvia, el estero El Realejo muestra prevalencia incluso en los meses de verano aunque en menor proporción.

El análisis de Salmonella spp demostró la ausencia de esta bacteria en este cuerpo de agua. Y el análisis de Vibrio parahaemolyticus demostró estar siempre dentro de los límites permisibles $<1.0 \times 10^{5} \mathrm{UFC} / \mathrm{ml}$.

\section{Discusión}

Los esteros sirven como desaguaderos naturales de las cuencas, esto quiere decir que todo lo que está depositado en el suelo de una cuenca con las lluvias será arrastrado hacia el cuerpo de agua, y luego, en el recambio de marea será arrastrada por la corriente hacia el mar.

E. coli tiene la característica de sobrevivir por tiempos prolongados en las materias orgánicas que se encuentran en los pastizales (Stoddard et al., 1998; Thelin y Gifford, 1983; y Moore, et al., 1989) y dado que el suelo de los pastizales es permeable debido al constante pastoreo del ganado vacuno, la materia orgánica es arrastrada más fácilmente por las lluvias (Porter, 1997).

Se observó claramente que los meses de la época lluviosa se caracterizaron por la mayor frecuencia de valores altos, mostrando cifras de valores altos en los meses de agosto y diciembre -de 89\% y 100\% respectivamente- en todas las estaciones muestreadas.

Los tres esteros estudiados durante esta investigación marcan un comportamiento similar. En los meses de verano los niveles de $E$. coli, están por debajo de los límites permisibles y en 
invierno aumentan. En cuanto a los análisis de correlación, sólo en el estero Padre Ramos dieron positivo con una valor del $23.8 \%$.

El mapa de uso del suelo nos permitió explicar las posibles causas de contaminación, coincidiendo con muchos autores que atribuyen la contaminación del agua a diversos factores, entre ellos la ganadería (Thelin y Gifford, 1983; Moore et al., 1989). Los puntos que reportaron mayores niveles de $E$. coli son los que colindan con los terrenos de pastizales y los puntos que estaban alejados de ellos registraron niveles más bajos.

Otro dato importante son los asentamientos humanos en los tres esteros, con poblaciones promedio de 8,000 habitantes (según el censo del INEC, 2005), la mayoría de esta población cuenta con letrina, pero estas letrinas están mal construidas y/o ubicadas, y por las características del suelo la permeabilidad es muy probable. Esto puede provocar que las bacterias se transporten a través del suelo hacia los cuerpos de agua (Coyne et al., 1996; Fulvio et al., 2004).

La bacteria Salmonella no se detectó en ninguno de los esteros estudiados.

Los análisis de Vibrio parahaemolyticus demuestran que esta bacteria estuvo predominantemente dentro de los límites permisibles. Cabe señalar que esta bacteria forma parte de la flora natural de aguas marinas, es patógena para algunas especies acuáticas por su característica de ser oportunista, que afecta al organismo acuático sólo cuando esté debilitado por estrés o por otra afectación.

La inocuidad en moluscos bivalvos se define como la característica que éstos deben poseer de estar libres de cualquier material extraño que presente un peligro a la salud humana. Esta característica puede verse afectada durante su producción, cosecha y/o extracción por problemas de contaminación debido a la industria, actividades agrícolas, ganaderas y asentamientos humanos (Centro de Investigación en Alimentos y Desarrollo, 2003) Por lo tanto, la selección adecuada del sitio de cultivo o extracción de este molusco hace que el riesgo de contaminación del producto disminuya.

La distribución de las "conchas negras", molusco bivalvo de mayor consumo nacional, se hace por medio de intermediarios. Los productos se pueden encontrar en mercados populares, supermercados, marisquerías, restaurantes y bares.

En la mayoría de los restaurantes se ignora el origen de estos moluscos y su estado de inocuidad. El riesgo aumenta debido a que éstos son consumidos crudos. Consumir un molusco contaminado con bacterias patógenas puede ocasionar infección gastrointestinal u otras enfermedades en el consumidor.

Los meses de mayor extracción y consumo son durante la época seca, especialmente durante la Semana Santa, que en algunos años coincide con la fecha de veda. Pero es en estos meses de veda donde se registran los niveles más bajos de E.coli en los esteros donde se extraen las conchas negras. Otra época de mayor consumo es el mes de diciembre, pero durante este mes se registró niveles elevados de E.coli en todos los esteros estudiados, pudiendo representar un riesgo consumir estos moluscos. 


\section{Conclusiones}

Los niveles elevados de $E$. coli corresponden en su mayoría a la época de lluvias, (junio octubre). En la época seca (enero - abril) la incidencia es casual.

El mes de diciembre es uno de los meses de mayor consumo de conchas negras a nivel nacional, pero durante este mes es cuando se registran los niveles más elevados de E.coli en los sitios de recolección de estos moluscos.

En relación a los tres esteros muestreados. El Realejo mostró la mayor prevalencia de muestras con valores superiores a lo recomendable. En dicho estero, el punto 3 fue el que indicó ser el punto más contaminado.

Todos los puntos que presentaron mayores niveles de contaminación están ubicados cerca de zonas de pastizales que nos indican ganadería en los alrededores.

Los esteros Padre Ramos y Aserradores mostraron niveles similares de muestras con niveles altos de E.coli. En ambos esteros el punto 2 fue el que reflejó menos niveles de contaminación.

\section{Recomendaciones}

Continuar el estudio de prevalencia de coliformes fecales en la carne de las conchas para conocer los valores de las mismas.

Proponer un Código de buenas prácticas de manejo para la extracción de las conchas.

Identificar la ubicación de la extracción del producto para certificar la calidad de agua de los sitios de extracción.

Estudiar la viabilidad de la veda en los meses de época seca, correspondiendo éstos a los valores más bajos de contaminación.

Si las conchas -o el agua de donde son extraídas- presentan niveles más altos que los permisibles, las conchas deberán ponerse en proceso de depuración.

En resumen, para asegurar la inocuidad de las conchas se deberá contar con un monitoreo de las zonas de extracción, certificación de las zonas y zonas de depuración en caso necesario.

En las zonas de extracción, es necesario hacer campañas de divulgación con las comunidades y también con los intermediarios de la cadena de comercialización, de manera que la venta de productos certificados logre mejores precios en los restaurantes y otros sitios de consumo. 


\section{Referencias bibliográficas}

APHA, AWWA, WEF. (1998). Satndard Methods for the Examination of water and wastewater. $20^{\text {th }}$ edition. Baltimore, Maryland.

CENTRO DE INVESTIGACIÓN EN ALIMENTOS Y DESARROLLO (2003) Manual de Buenas Prácticas de Producción Acuícola de Moluscos Bivalvos para la inocuidad alimentaria. A.C. México: Unidad Mazatlán en Acuicultura y Manejo Ambiental.

CEPIS Centro Panamericano de Ingeniería Sanitaria (1986). Calidad del agua en el medio marino. Historia y aplicación de normas bacteriolólogicas. 27 pág.

CIDEA (2005) Estudio de mercado de moluscos, ostras, mejillones y almejas en Centroamérica y del mercado interno de conchas negras en Nicaragua. Mimeo.

COYNE, M.; STODDARD, C.; GROVE, J. \& THOM, W. (1996) Infiltration of Faecal Bacteria Through Soils: Timing and Tillage Effects. Disponible en: http//www.uky.edu/Ag/ Agronomy/Extension/ssnv/ssv 174.htm. Consultado: octubre de 2007.

DAVIES, C. M.; LONG, J.A.H.; DONALD, M. \& ASHBOLT, N.J. (1995) "Survival of faecal microorganisms in marine and freshwater sediments". Applied and Environmental Microbiology. 61(5): $1888-1896$.

DEWEDAR, A. \& BAGHAT, D.M. (1995) "Fate of Faecal Coliform Bacteria in a Wastewater Retention Reservoir Containing Lamna gibba”. En Wat. Res. 29(11):2598 - 2600.

DONSEL, D.; GELDREICH, E. \& CLARKE, N. (1967) "Seasonal Variation in Survival of Indicator Bacteria in Soil and their Contribution to Storm-Water". En Applied Microbiology. 15(6):1362 -1370.

FDA (2004) Bacteriological Analytical Manual Online. Disponible en: http://www.cfsan. fda.gov/ ebam/bam-toc.html. Consultado: octubre de 2007.

FULVIO, M.; VARCAMONTI, M. \& NALCLERIO, G. (2004) "Influence of Precipitation and Soil on Transport of Fecal Enterococci in Fractured Limestone Aquifers". En Applied and Environmental Microbiology. 4(17):2843-2847.

INEC (2005) VIII Censo de Población y IV de Vivienda. Disponible en: http://www.inec. gob.ni/censos2005/VolPoblacion/Volumen\%20Poblacion\%201-4/Vol.IV\%20PoblacionMunicipios.pdf Consultado: octubre de 2007.

JAHNCKE, M.; SPENCER G.; REILLY A.; MARTIN, R. \& COLE, E. (2002). Public, Animal, and Environmental Aquaculture Health Issues. USA: John Wiley and Sons.

KRESS, M. \& GIFFORD, G. (1984). "Faecal Coliform Release from Cattle Faecal Deposits". En Water Resources Bulletin. 20(1):61-66.

LA GACETA, DIARIO OFICIAL (2002) Resolución Ministerial No 54-02: Actualizar el sistema de vedas de especies silvestres. Managua: Gobierno de la República de Nicaragua.

MIFIC (2004) NTON 03003 04: Criterios microbiológicos aplicables a los productos pesqueros y acuícola frescos y congelados. Managua: Comisión Nacional de Normalización Técnica y Calidad, Ministerio de Fomento Industria y Comercio.

MIFIC (2005) Norma técnica nicaragüense. NTN 04001 05; Requisitos Generales para la competencia de los laboratorios de ensayo y de calibración. Managua: Comisión Nacional de Normalización Técnica y Calidad, Ministerio de Fomento Industria y Comercio. 
MOORE J.; SMITH, J.; BAKER, E.; MINER, J. \& MOFFITT, D. (1989). "Modelling Bacteria Movement in Livestock Manure Systems". En Transaction of the ASAE. 32 (3):10491053.

PORTER, M. (1997) Programa nacional de competitividad Nicaragua: Análisis de sostenibilidad de la industria ganadera en Nicaragua. Disponible en: http://www. agenda21.org.ni/. Consultado: octubre de 2007.

STODDARD, C.; COYNE, M. \& GROVE, J. (1998). "Fecal Bacteria Survival and Infiltration Through a Shallow Agricultural Soil: Timing and Tillage Effects". En J. Environmental. Qual. 27:1516-1523.

THELIN, R. \& GIFFORD, G. (1983) "Fecal Coliform Release Patterns from Material of Cattle". En J. Environ. Qual. 112(1):57-63. 